Erratum

\title{
Erratum: Yuan, B., et al. Household Registration System, Migration, and Inequity in Healthcare Access. Healthcare 2019, 7, 61
}

\author{
Bocong Yuan ${ }^{1}{ }^{(}$, Jiannan $\mathrm{Li}^{2, *}{ }^{2}$, Zhaoguo Wang ${ }^{1, *} \mathbb{( D}$ and Lily $\mathrm{Wu}^{1}$
}

1 School of Tourism Management, Sun Yat-sen University, West Xingang Rd. 135, Guangzhou 510275, China; yuanbc@mail.sysu.edu.cn (B.Y.); wull9@mail2.sysu.edu.cn (L.W.)

2 International School of Business \& Finance, Sun Yat-sen University, West Xingang Rd. 135, Guangzhou 510275, China

* Correspondence: lijnanna@mail.sysu.edu.cn (J.L.); wzglinyi2007@163.com (Z.W.)

Received: 24 April 2020; Accepted: 25 May 2020; Published: 3 June 2020

Some details about author affiliations should to be updated in the article [1]. We sincerely apologize to our editor, all editorial staff, the publisher and our readers for any inconvenience.

Bocong Yuan, Zhaoguo Wang and Lily Wu are currently affiliated to the School of Tourism Management, Sun Yat-sen University.

Jiannan $\mathrm{Li}$ is currently affiliated to the International School of Business \& Finance, Sun Yat-sen University.

The corrected author list is provided below:

Bocong Yuan ${ }^{1}$, Jiannan $\mathrm{Li}^{2, *}$, Zhaoguo Wang ${ }^{1, *}$ and Lily Wu ${ }^{1}$

${ }^{1}$ School of Tourism Management, Sun Yat-sen University, West Xingang Rd. 135, Guangzhou 510275, China; yuanbc@mail.sysu.edu.cn (B.Y.); wull9@mail2.sysu.edu.cn (L.W.)

2 International School of Business \& Finance, Sun Yat-sen University, West Xingang Rd. 135, Guangzhou 510275, China.

*Correspondence: lijnanna@mail.sysu.edu.cn (J.L.); wzglinyi2007@163.com (Z.W.)

\section{References}

1. Yuan, B.; Li, J.; Wang, Z.; Li, L. Household Registration System, Migration and Inequity in Healthcare Access. Healthcare 2019, 7, 61. [CrossRef] [PubMed]

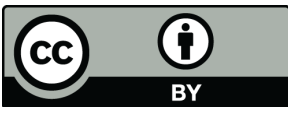

(C) 2020 by the authors. Licensee MDPI, Basel, Switzerland. This article is an open access article distributed under the terms and conditions of the Creative Commons Attribution (CC BY) license (http://creativecommons.org/licenses/by/4.0/). 